\title{
El principio de progresividad y no regresividad laboral en el cambio jurisprudencial: examen del beneficio de incremento pensional por persona a cargo
}

\author{
Recibido: 4 de agosto de 2020 - Aprobado: 28 de septiembre de 2020 \\ https://doi.org/10.22395/ojum.v20n42a7
}

\author{
José Guillermo Espinosa Hios \\ Universidad de la Amazonia, Florencia, Colombia \\ jo.espinosa@udla.edu.co \\ https://orcid.org/0000-0002-9543-0243
}

\section{RESUMEN}

El objetivo del presente artículo es trazar algunas consideraciones en torno al principio de progresividad y no regresividad en los derechos sociales de los trabajadores. Este principio, como se sabe, encuentra arraigo normativo tanto en el plano nacional como internacional, y se hace exigible no solo al legislador, sino también a las demás ramas de poder público. Particularmente, a la rama judicial en ejercicio de las competencias que constitucional y legalmente le han sido encomendadas. Para lo anterior el ensayista se vale de un análisis documental de la jurisprudencia expedida en torno a la temática del incremento pensional por familiar a cargo, beneficio extrapensional y accesorio a la pensión mínima. Este auxilio se encontraba consagrado en el Acuerdo 049 (1990) y reglamentado por el Decreto 758 (1990). Desde esta óptica, el objetivo central del escrito es revelar el escenario jurídico creado a partir de la expedición de la Sentencia SU-140/19 (2019) proferida por la Corte Constitucional de Colombia en su función de máxima intérprete de la Constitución Política. Una vez analizada la jurisprudencia expedida en esta cuestión, planteo a modo de conclusión la siguiente premisa: las altas cortes de Colombia en ejercicio de su función de unificar jurisprudencia no deben desconocer el mandato de progresividad y no regresividad laboral, por cuanto el mentado principio no se predica únicamente de los cambios legales, sino también de las variaciones jurisprudenciales.

Palabras clave: incremento pensional; imprescriptibilidad pensional; favorabilidad e inescindibilidad de la ley; in dubio pro operario; progresividad en los derechos sociales. 


\title{
The Principle of Labor Progressivity and Non-regressiveness in the Jurisprudential Change: an Exam on the Retirement Pay Increase per Person in Charge of
}

\begin{abstract}
The objective of this article is to trace some considerations surrounding the principle of progressivity and non-regressiveness in the worker's social rights. This principle, as it is known, is settled both on national and international grounds and can be demanded not only to the legislator but also to the other branches of the public Power, particularly to the judicial branch in the exercise of its legal and constitutional competencies. For that, the author performs a documental analysis of the jurisprudence on the retirement pay increase per person in the care of, extra-retirement pay benefit, and minimum retirement pay topics. This aid is described in Agreement 049 (1990) and is ruled by Decree 758 (1990). From this perspective, the main objective of this article is to reveal the judicial scenery created by the SU-140/19 Sentence (2019) ruled by the Colombian Constitutional Court in its maximum function of interpreting the Political Constitution. Once the jurisprudence is analyzed, the article states as a conclusion that the Colombian higher courts, in the exercise of their function of unifying the jurisprudence must not disown their duty to labor progressivity and non-regressiveness for as much as this principle is not only related to legal changes but also jurisprudential ones.
\end{abstract}

Keywords: retirement pay increase; retirement pay imprescriptibility; favorability and inescindibility of the law; in dubio pro operario; progressivity on social rights. 


\section{INTRODUCCIÓN}

El presente artículo es derivado del trabajo académico titulado: Análisis normativo de las medidas laborales y de seguridad social expedidas por el gobierno colombiano frente a la pandemia de la Covid-19: una mirada desde el principio de progresividad y no regresividad en los derechos sociales (2020). Dicho trabajo de grado fue presentado como requisito parcial para optar al título de abogado en la Universidad de la Amazonia (Colombia); fue elaborado entre los meses de marzo a octubre de 2020 y el director encargado de acompañar su proceso fue el docente Mauricio Alonso Epia Silva. Además, este trabajo se adscribe a la línea de investigación en derechos humanos establecida por la referida alma mater.

Por otra parte, el artículo tiene como propósito analizar el precedente jurisprudencial establecido en la temática de incremento pensional por persona a cargo. Este estudio se realiza desde el tamiz del principio de progresividad y no regresividad en los derechos sociales de los trabajadores con el fin de establecer cómo dicho principio actúa como parámetro de control de la labor de unificar jurisprudencia por parte de las altas cortes de Colombia.

Para dicha tarea, inicialmente es necesario rememorar que la Ley 100 (1993) creó en Colombia un nuevo régimen de seguridad social integral, conformado por tres subsistemas, a saber, el sistema general de seguridad social en pensión, el sistema general de seguridad social en salud y el sistema general de riesgos profesionales. Así mismo, se incluyó, unos beneficios adicionales llamados servicios complementarios, esto es, auxilios económicos que buscan garantizar un ingreso mínimo a la población adulta que se encuentre en estado de labilidad y no tenga cómo garantizarse un sustento diario.

Como se sabe, antes de la promulgación de esta ley, Colombia tenía reglamentado cada subsistema en distintas normas que codificaban y describían cada uno de los tres sistemas de seguridad social mencionados anteriormente. Esta situación permitía que existiera una dispersión normativa en la materia. En este sentido, con la expedición de la referida ley se quiso superar algunos males endógenos que yacían al interior del sistema de seguridad social en pensión. Entre ellos, como lo señala Arrieta (2011), el sistema se caracterizaba por su baja cobertura; la multiplicidad de regímenes pensionales; la falta de adecuación entre la edad de retiro, las nuevas condiciones demográficas y la esperanza de vida de la población colombiana; altos costos administrativos; inequidad y su poca o escasa sostenibilidad financiera.

De igual manera, en el artículo 36 de la mentada ley se previó la existencia de un régimen de transición a fin de no afectar los derechos adquiridos por la población que ya estaba próxima a pensionarse. Lo anterior supuso que a algunas de las pensiones reconocidas en vigencia de la Ley 100 (1993) no le fuera aplicable dicho marco normativo, en tanto estas estaban cobijadas por lo reglamentado en normas anteriores. 
De esta forma, los beneficiarios del régimen de transición pensional previsto en el inciso segundo del artículo 36 de la Ley 100 (1993), para establecer la norma anterior que le era aplicable, debían saber que ello dependía de la entidad o empresa en donde se encontraba laborando - pública o privada-. De este modo, para los empleados del sector privado era aplicable el régimen general previsto en el Acuerdo 049 (1990) y aprobado por el Decreto 758 (1990). Estos estaban afiliados al extinto Instituto de Seguros Sociales (ISS), hoy Colpensiones.

Por otra parte, a los empleados públicos se les aplicaba -dependiendo de la entidad en donde laboraban- la Ley 33 (1985) o la Ley 71 (1988) y el régimen general pensional público. Todo dependía de si el empleado estaba afiliado a Cajanal o a otra caja departamental, distrital o municipal administradora de los regímenes de previsión social. Así mismo, coexistían algunos regímenes especiales, previstos en el Decreto 546 (1971), para los servidores de la rama judicial y del Ministerio Público; los previstos en el Decreto 929 (1976), para los empleados de la Contraloría General de la República; otros, previstos en el Decreto 2701 (1988), para los servidores vinculados a entidades adscritas o vinculadas al Ministerio de Defensa; y la Ley 4 (1992) para magistrados de las altas cortes, congresistas y demás altos dignatarios del país.

De acuerdo con lo anterior, en el Decreto 758 (1990), aprobatorio del Acuerdo 049 (1990), se reglamentaba el beneficio extrapensional de incremento pensional por familiar a cargo. Este beneficio era un auxilio consistente en un aumento a la pensión mínima legal del 7 \% o $14 \%$ para aquel pensionado que cumpliera con los requisitos establecidos en el artículo 21 y siguientes del referido acuerdo. En un primer caso, dicho beneficio se otorgaba a los pensionados que tuvieran a su cargo uno o más hijos menores de dieciséis años; de dieciocho años si se acreditaba la condición de estudiante; o hijos de cualquier edad que padecieran de alguna discapacidad, no recibieran pensión y dependieran económicamente del pensionado. Por su parte, el incremento pensional sería de $14 \%$ en aquellos casos en donde el jubilado recibiera una mesada pensional mínima y su cónyuge o compañera permanente dependiera económicamente de él.

Por su parte, en cuanto a la naturaleza del beneficio de incremento pensional por persona a cargo, es menester indicar que este es de carácter transitorio y no vitalicio, como si ocurre con el derecho a la pensión. En este sentido, conforme a lo reglamentado en el artículo 22 del Acuerdo 049 (1990), el acrecentamiento pensional, como derecho accesorio y que no forma parte integral de la pensión de invalidez o de vejez, solo subsiste mientras perduren las causas que les dieron origen. Por tal motivo, si desaparece el deber del pensionado de solventar los gastos de sus hijos, cónyuge o compañera permanente, no es posible que este entre a reclamar su pago.

Ahora bien, la jurisprudencia de la Sala Laboral de la Corte Suprema de Justicia, como órgano de cierre de la jurisdicción ordinaria laboral, recientemente venía reco- 
nociendo el auxilio de incremento pensional a favor de aquellos jubilados que hayan accedido al reconocimiento de su pensión por derecho propio o con ocasión del régimen de transición previsto en el inciso segundo del artículo 36 de la Ley 100 (1993). En este sentido, la Corte Suprema de Justicia, en virtud del principio de favorabilidad e inescindibilidad de ley laboral, había sentado el criterio conforme al cual, pese a la promulgación de una nueva normatividad, aquellos trabajadores que estuvieran cobijados por el Acuerdo 049 (1990) y su decreto reglamentario, les era posible acceder al derecho contenido en el referido acuerdo, siempre y cuando disfrutaran de una pensión mínima, vital y móvil.

No obstante, el panorama jurisprudencial dio un giro de $180^{\circ}$ a partir de un último pronunciamiento efectuado por la Corte Constitucional de Colombia. Esto a través de la Sentencia SU-140/19 (2019), en la cual este tribunal unificó jurisprudencia en lo relativo a la imprescriptibilidad del incremento pensional por persona a cargo. En aquella oportunidad, el máximo órgano de la justicia constitucional indicó que frente al referido beneficio extrapensional había operado la derogatoria orgánica.

A la vista de lo expuesto, para este tribunal, la derogatoria tácita había operado en virtud de lo consagrado en el artículo 3 de la Ley 153 (1887) y en lo normado en los artículos 71 y 72 del Código Civil (1887) colombiano. En pocas palabras, para la Corte Constitucional el respectivo derecho resultaba incompatible con el artículo 48 constitucional, a partir de la modificación realizada por el Acto Legislativo 01 (2005), con el cual se eleva a rango constitucional la regla de sostenibilidad financiera.

En este sentido, cada ley que se expida con posterioridad al aludido acto legislativo debe regirse por un marco de sostenibilidad económica de las disposiciones o pautas que allí se establezcan (Duque y Duque, 2016). Además, puesto que a juicio de la Corte la ultractividad prevista en la ley 100 solo opera frente a los requisitos de edad, tiempo de servicios y monto de la pensión, en estos aspectos, es aplicable el régimen pensional anterior. Por lo tanto, no puede hacerse extensivo a beneficios extrapensionales accesorios, como bien puede personificar el beneficio de incremento pensional estatuido en el Decreto 758 (1990), en tanto este no fue dotado de naturaleza pensional por expresa disposición legal.

Para lo anterior es necesario clarificar que, conforme a lo normado en el artículo 22 del Acuerdo 049 (1990), los incrementos pensionales no forman parte integral de la pensión de invalidez o de vejez que haya reconocido el Instituto de Seguros Sociales (ISS), hoy Colpensiones. Por esta razón, en principio, tampoco gozaría del atributo de imprescriptibilidad que es propio e inherente al derecho a una pensión mínima, vital y móvil.

Así las cosas, el objetivo del presente artículo es plasmar algunas reflexiones en torno a la discusión que surge en relación con la vigencia del incremento pensional 
por persona a cargo. Para ello, a partir de un método cualitativo de tipo descriptivo, se estudia los principales pronunciamientos efectuados por la Corte Suprema de Justicia, el Consejo de Estado y la Corte Constitucional de Colombia, con relación a la temática en cuestión.

En particular, se defiende la tesis según la cual el principio de progresividad y no regresividad, en los derechos sociales, actúa como un estándar jurídico que imposibilita a los órganos jurisdiccionales, en ejercicio de su labor de unificar jurisprudencia, cambiar o variar el criterio jurisprudencial en perjuicio de los mínimos de protección alcanzados en materia laboral y de seguridad social.

Pues, en cierto modo, la variación interpretativa que se pretende introducir con la Sentencia SU-140/19 (2019) va en contravía de las obligaciones internacionales suscritas por el Estado colombiano. En este sentido, se afecta el derecho a la igualdad y no regresividad de los derechos sociales de aquellos ciudadanos que tienen procesos pendientes por resolver en la sede administrativa o judicial, en el problemático, pero muy probable evento de acogerse el criterio jurisprudencial sentado por la Corte Constitucional de Colombia. Por este motivo, se explican algunas alternativas legales de las que pueden hacer uso los operadores jurídicos a fin de apartarse del cambio jurisprudencial que plantea la Sentencia SU-140/19 (2019).

\section{BREVES CONSIDERACIONES AL RÉGIMEN PENSIONAL ANTERIOR A LA LEY 100 DE 1993}

Como lo expresa Salcedo (2017) y Muñoz et al. (2009), el surgimiento del moderno sistema pensional colombiano se remonta a la década de los cuarenta, al menos con una organización de seguros sociales propiamente dicha. Por otro lado, anterior a este periodo de conformación institucional, como lo expresa Ortiz y Arroyave (2015), se argumentaba que la asistencia pública era un deber del Estado que se garantizaba para quienes carecían de medios de subsistencia, de derecho para exigirla a otras personas, o estaban disminuidos física y psicológicamente.

A partir de allí, con la Ley 6 (1945) se crea la Caja Nacional de Previsión Social (Cajanal) y se empieza a forjar el esquema pensional colombiano. En aquellos tiempos, el sistema de previsión social no tenía la estructura institucional que conocemos hoy en día. Es por lo anterior que, de acuerdo con lo expresado por Fedesarrollo (2010), para aquel entonces se comenzó a gestar un incipiente plan de pensiones caracterizado por la presencia de un millar de cajas de previsión social de orden municipal y departamental que cubrían los riesgos únicamente de los empleados del sector público. El esquema funcionaba de la siguiente forma: usualmente cada empresa, o sector público, tenía su propia caja de previsión para la administración de los riesgos de vejez, invalidez y salud.

De esta forma, tan solo para el año 1967, las pensiones de los trabajadores del sector privado se reglamentaron y se volvieron obligatorias. Para la consecución de este 
objetivo se encomendó la administración del régimen pensional privado al Instituto Colombiano de los Seguros Sociales (ICSS), como una entidad técnica encargada de administrar el régimen de seguros obligatorios. Este régimen fue creado con la Ley 90 (1946) y entró en funcionamiento mediante el Decreto 2347 (1948), que para el año de 1977 cambió su nombre a Instituto de Seguros Sociales (ISS), actualmente Colpensiones.

De este modo, el subsistema de pensiones de los trabajadores privados funcionaba de manera diferente al de los empleados públicos, ya que no contaba con los beneficios y privilegios de estos últimos. Esta situación de distribución regresiva de los recursos afectaba la eficiente administración del sistema e imposibilitaba, a su vez, la sostenibilidad fiscal del mismo. Un ejemplo de lo anterior es que de acuerdo con lo señalado por Muñoz et al. (2009), en Cajanal se otorgaban pensiones que eran en promedio $66 \%$ superiores a las pensiones otorgadas por el ISS. De igual forma, en algunos casos se presentaban eventos en donde las cajas de previsión social de orden local otorgaban pensiones de vejez de $150 \%$ y hasta $350 \%$ por ciento superiores a las pensiones de vejez correspondientes al esquema del Instituto de Seguros Sociales.

Adicionalmente, otro problema que presentaba el sistema de previsión social anterior tenía que ver con los regímenes especiales. En Ecopetrol, por ejemplo, los empleados no cotizaban y recibían una pensión del $75 \%$ de su último salario, con un rango de edad de cincuenta y cinco años. Este mismo hecho se presentaba con los afiliados al Fondo de Prestaciones Sociales del Magisterio (Fomag), quienes, además de recibir una pensión, tenían derecho a recibir una pensión de concurrencia (Fedesarrollo, 2010, pp. 6-7).

De esta manera, para la década de los noventa, con la promulgación de la Carta Política (1991) y, posteriormente, con la expedición de la Ley 100 (1993), se quiso superar, entre otros males, el déficit de equidad social y la escasa sostenibilidad fiscal que yacía en el esquema pensional anterior, caracterizado por la dispersión normativa y la falta de homogeneidad del sistema.

Por ello, con la Ley 100 se unificó el sistema pensional colombiano y se creó, de manera paralela al régimen de prima media, un régimen alternativo, en el cual cada afiliado debe construir su pensión mediante un sistema de capitalización en un fondo privado. Esto, a través del pago periódico de cotizaciones en una cuenta individual, en la cual se depositan los recursos ahorrados por cada trabajador (Ortiz y Arroyave, 2015).

En este régimen, como lo ha manifestado la Corte Constitucional en la Sentencia C-754/04 (2004), el monto total de la pensión es variable y puede depender de varios factores. Por ejemplo, el monto acumulado en la cuenta, la edad de retiro del afiliado, la modalidad de la pensión escogida, las semanas cotizadas, y los rendimientos obtenidos por los ahorros acumulados. 
Sin embargo, como lo expresa Muñoz et al. (2009), pese al funcionamiento del nuevo régimen pensional instaurado por la Ley 100 (1993), los afiliados al sistema que al 1 de abril de 1994 -fecha a partir de la cual entro en vigor la Ley 100-cumplieran ciertas características siguieron cubiertos por el régimen anterior. Estas características eran: ser mujer mayor de treinta y cinco años; hombre mayor de cuarenta años; o trabajadores que llevaran al menos quince años de servicios cotizados. Este grupo de trabajadores conformaron el régimen de transición de la Ley 100, y para acceder a su pensión se beneficiaron de las disposiciones contenidas en los reglamentos anteriores.

De este modo, a los trabajadores del sector privado que cumplieran con los requisitos señalados en líneas anteriores, y que estuvieran afiliados al extinto Instituto de Seguros Sociales (ISS), hoy Colpensiones, les era aplicable el régimen pensional que se encontraba previsto en el Acuerdo 049 (1990) y aprobado por el Decreto 758 (1990), en el cual se encontraba establecido el beneficio de acrecentamiento pensional.

En definitiva, los trabajadores, de conformidad a lo normado en los artículos 12 y 20 del referido acuerdo, para acceder a la pensión tuvieron que cumplir con los siguientes requisitos: ser hombre de sesenta o más años de edad; ser mujer de cincuenta y cinco o más años de edad; y tener un mínimo de quinientas semanas de cotización pagadas durante los veinte años anteriores al cumplimiento de las edades mínimas, o en su caso, acreditar un número de mil semanas de cotización, sufragadas en cualquier tiempo.

En este sentido, en el caso de que el afiliado no haya podido cumplir con las quinientas semanas de cotizaciones mínimas dentro los veinte años anteriores al cumplimiento de la edad, solo podía acceder a la pensión de vejez una vez hubiese acreditado mil semanas de cotización en cualquier tiempo.

\section{EL BENEFICIO DE INCREMENTO PENSIONAL DEL QUE TRATA EL ACUERDO 049 Y EL DECRETO 758 DE 1990}

El Acuerdo 049 (1990) y su decreto aprobatorio consagran a favor de los pensionados de origen común un incremento porcentual sobre su mesada pensional, en aquellos eventos en donde el jubilado reciba una pensión por derecho propio o en virtud del régimen de transición previsto en el artículo 36 de la Ley 100 (1993). En estos dos casos el pensionado debe acreditar los siguientes requisitos: a) ser beneficiario de una pensión mínima; b) tener bajo su cargo a su cónyuge o pareja permanente, hijos menores de dieciséis años o de dieciocho años si es estudiante, o hijos de cualquier edad que tenga alguna discapacidad física o sensorial; y c) demostrar que los hijos dependen económicamente del pensionado.

Sin embargo, el reconocimiento de este beneficio extrapensional se ha visto comprometido a raíz de una disputa interpretativa que se remonta al año 2005 y que perdura en la actualidad. La referida discrepancia hermenéutica ha involucrado 
a los órganos de cierre de las tres más importantes jurisdicciones del país. Tanto la Corte Suprema de Justicia, como el Consejo de Estado y la Corte Constitucional de Colombia han realizado, en el marco de sus competencias, pronunciamientos que resultan contradictorios. En este sentido, se está originando graves perjuicios en los derechos de la clase trabajadora.

En efecto, como lo apunta Rodas y Arenas (2019), esta última corporación se ha sumergido entre dos posturas: una restrictiva y la otra amplificadora. Esto en relación con la imprescriptibilidad o no del incremento pensional por familiar a cargo. No obstante, este debate medular pasó a un segundo plano después de que dicho Tribunal de Justicia haya unificado su criterio mediante la Sentencia SU-140/19 (2019), expedida en remplazo de la Sentencia SU-310/17 (2017) y que fue anulada en su momento por el Auto 320 (2018).

En las siguientes líneas intento plasmar algunas consideraciones de por qué dicha decisión no parece la más acertada desde la perspectiva de los derechos sociales de los trabajadores. Ya que una tesis restrictiva como la trazada por este alto tribunal no armoniza con los compromisos internacionales que han sido arrogados por el Estado colombiano. Para dicho análisis me sirvo de algunos pronunciamientos que han sido proferidos tanto por la Corte Suprema de Justicia, como por la propia Corte Constitucional de Colombia. Allí se ha reconocido la legitimidad de los incrementos pensionales ante el silencio que guardó al respecto la Ley 100 (1993).

Particularmente, sobre este tema, para el año 2017 el Consejo de Estado, en ejercicio de sus competencias constitucionales y legales, tuvo la oportunidad de pronunciarse sobre la legalidad del incremento pensional mencionado en el Decreto 758 (1990). En aquella oportunidad, esta máxima corporación de la justicia contenciosa administrativa expresó lo siguiente:

Además, si bien es cierto, la ley 100 de 1993 determinó que derogaba todas las disposiciones que le fueran contrarias o que la modificaran. Así mismo es preciso tener en cuenta, que también determinó acerca de la salvaguardad de los derechos adquiridos y del régimen de transición; lo que significa, que se constituye en deber legal el respeto por el derecho adquirido, que le asiste a los jubilados por invalidez o por vejez al amparo el Acuerdo 49 de 1990, al reconocimiento y pago de los incrementos pensionales por familiares a cargo, siempre que se presenten esas especiales circunstancias en estos últimos, que se determinan expresamente en dicho acuerdo. [...] Por manera, que al no haber sido regulada en forma integral por la Ley 100 de 1993, la materia referida a los incrementos, y por el respeto a los derechos adquiridos de quienes se jubilaron por invalidez o por vejez de conformidad con el ordenado por el Acuerdo 049 de 1990, es evidente que no se produjo la derogatoria orgánica. (Sentencia 2741-08/17, 2017)

De esta forma, la disparidad de criterios esgrimidos por los tres más importantes tribunales de cierre del país está ocasionando graves perjuicios en la ciudadanía del 
común, al afectar la seguridad jurídica en materia pensional. Particularmente, con la Sentencia SU-140/19 (2019) la Corte Constitucional de Colombia adopta una medida que resulta regresiva y totalmente ajena a la jurisprudencia que ha proferido en relación con el deber de protección del derecho a la seguridad social en el ámbito de las pensiones.

Además, con la sentencia en cita se transgreden otros principios de raigambre constitucional, como lo son el principio de favorabilidad e inescindibilidad de la ley laboral, los cuales encuentran en el artículo 53 de la Constitución Política su fundamento sustantivo. Así mismo, es menester recordar que la Convención Americana sobre Derechos Humanos (CADH), aprobada mediante Ley 16 (1972), consagra en su artículo 26 el principio de progresividad en los derechos sociales. Esto supondría que, eventualmente, las personas que han visto afectadas sus garantías iusfundamentales, acudan al Sistema Interamericano a fin de lograr la protección internacional de sus derechos.

Lo anterior es suficiente para formular el siguiente interrogante: ¿Es posible considerar que con la expedición de la Sentencia SU-140/19 (2019) el Estado colombiano quebranta el principio objetivo de progresividad que informa todo derecho de contenido social? Y, de manera consecuente, ¿cabría alguna probabilidad de atribuir responsabilidad al Estado colombiano por contravenir el compromiso asumido conforme al artículo 26 de la CADH? Lo anterior en razón a que, la citada cláusula convencional, establece que todos los Estados parte deben procurar por todos los medios apropiados la plena efectividad de los derechos sociales, hasta el máximo de los recursos disponibles.

Así mismo, resulta oportuno traer a colación un pronunciamiento efectuado por el Consejo de Estado. El pronunciamiento tuvo lugar cuando se discutía sobre los factores salariales a tener en cuenta para la liquidación pensional y el ingreso base de liquidación aplicable a los pensionados cobijados por el régimen de transición previsto en el artículo 36 de la Ley 100 (1993). En aquella oportunidad, esta máxima corporación de la justicia contenciosa administrativa se apartó del criterio jurisprudencial sentado por la Corte Constitucional mediante la Sentencia SU-230 (2015), al considerar que dicha decisión iba en contravía del principio de igualdad y progresividad en los derechos sociales de los trabajadores. Allí mismo se consignó el siguiente considerando:

En efecto, si ya la Constitución dispuso la finalización del régimen de transición pensional y queda pendiente, en consecuencia, un volumen de reconocimientos pensionales mucho menor que el que ya tiene decidido el asunto conforme a la jurisprudencia del Consejo de Estado, no se ve ninguna afectación del principio de sostenibilidad financiera que imponga el cambio jurisprudencial que plantea la sentencia SU-230 de 2015, y en cambio sí se hace notorio y protuberante el desconocimiento de los principios de igualdad y de progresividad. (Sentencia 4683-13/16, 2016) 
De tal forma, como bien lo puso de presente el Consejo de Estado, en la aludida sentencia, no resulta razonable que se acuda al principio de sostenibilidad fiscal para entrar a desconocer principios de mayor peso constitucional, sobre todo, en aquellos eventos en donde existe una laguna normativa en la materia. En estos casos, ante el vacío normativo o de ambigüedad jurídica en la materia, se debe propender por aquella interpretación que amplíe el rango de protección de los derechos laborales, y de ninguna forma entrar a reducir el ámbito de protección de la norma jurídica.

Como se expresó en líneas anteriores, el fallo de la Corte Constitucional constituye una franca vulneración al principio de progresividad y no regresividad que es inherente a los derechos sociales. De esta manera, como lo expresa Courtis et al. (2006), el mandato de progresividad, por ser una garantía de carácter sustantivo, veda al legislador -negativo y positivo-, y al titular del poder reglamentario, de la potestad de acoger reglamentaciones o resoluciones que deroguen, reduzcan, o hagan resurgir obstáculos que limitan el nivel de protección alcanzado en los derechos económicos, sociales y culturales.

La conclusión es, a mi modo de ver, que la prohibición de no regresividad laboral se hace exigible con mayor fuerza al órgano judicial que, en un estado normal de las cosas, debería ser el encargado de garantizar su no quebrantamiento. El axioma es sencillo: si el principio de progresividad y no regresividad en los derechos sociales ha sido reconocido por la jurisprudencia constitucional como parte del sistema jurídico colombiano, en virtud del bloque de constitucionalidad, no sería factible que se arguyera que su operatividad solo se ve reducida a los cambios legales, y no frente a los cambios jurisprudenciales.

Aquí ha de tenerse en cuenta que la prohibición de regresividad o de retroceso en materia social, como estándar de juicio, encuentra su cimiento en los principios de seguridad jurídica y confianza legítima. Estas son nociones que la misma Corte Constitucional se ha encargado de esclarecer mediante su desarrollo jurisprudencial.

Sobre el particular, Christian Courtis et al. (2006) ha expresado lo siguiente:

la prohibición de regresividad supone la extensión de este principio al campo de las posiciones jurídicas creadas por normas y medidas de carácter social. Se trata, en alguna medida, de la consecuencia de la adopción de un modelo de Estado de derecho de carácter social, o Estado social de derecho. [...] en el Estado social de derecho se extiende la protección de la confianza y el estatuto de seguridad jurídica también a las conquistas sociales, de modo que, en lugar de beneficios revocables, las normas de orientación social también conceden derechos con vocación de estabilidad. (p. 18)

De tal manera, el modelo de Estado social de derecho incorporado en nuestra Carta Política (1991) impone sobre los poderes públicos y, particularmente, sobre los órganos que integran la rama judicial, la obligación de encauzar su rumbo a fin de 
lograr la igualdad material o sustantiva entre todos los ciudadanos. Máxime si se tiene en cuenta que, como lo expresa Courtis et al. (2006), la proyección de este principio se extiende a la protección especial de aquellas personas que están en una situación peor, en tanto carecen de los medios - materiales y jurídicos- para la satisfacción de sus necesidades básicas.

Dicho lo anterior, en los siguientes epígrafes me ocupo de la tarea de revelar, en primer lugar, la postura con mayor acogida dentro de la Corte Suprema de Justicia, con relación a la vigencia de los incrementos pensionales de los que trata el Acuerdo 049 (1990). En segundo lugar, identifico algunos pronunciamientos que constituyen la línea jurisprudencial depurada por la Corte Constitucional de Colombia en la materia, en la mayoría de ellos, en sede de revisión de tutela y de unificación de jurisprudencia. Eso sin desconocer que dentro de dicho tribunal el tema no ha sido tratado de forma pacífica y que hasta hace tan solo un año no se tenía un criterio unívoco.

Así mismo, se analiza cómo a partir de la expedición de la Sentencia SU-140/19 (2019), en lugar de superarse el problema de la disparidad de criterios y, por consiguiente, la inseguridad jurídica que predomina en la materia, dichas contradicciones se han hecho más latentes. De esta manera, en algunos tribunales del país -en sede de segunda instancia o grado jurisdiccional de consulta- se han adoptado decisiones jurídicas disímiles y, en algunos casos, niegan el derecho con base en el nuevo criterio jurídico sentado por la Corte Constitucional de Colombia. En otros casos, reconocen el derecho y, por tanto, se apartan del criterio jurisprudencial derivado de la Sentencia SU-140/19 (2019).

El referido panorama judicial ha generado un estado de incertidumbre o inseguridad jurídica. En este sentido, en virtud del principio de autonomía e independencia judicial que es propio del ejercicio jurisdiccional conforme al canon 228 constitucional y a la Ley Estatutaria 270 (1996), corresponde a cada despacho escoger y apadrinar la postura hermenéutica edificada por la máxima corporación de la justicia ordinaria o, por el contrario, inclinarse por el último criterio de unificación que fue desarrollado por la Corte Constitucional de Colombia. Esto último resulta, como se ha advertido, regresivo en cuanto a los derechos sociales de los trabajadores, porque desconoce su propio desarrollo jurisprudencial.

\section{JURISPRUDENCIA DE LA CORTE SUPREMA DE JUSTICIA}

En esta materia, pese a la disparidad de criterios que se ha hecho evidente en algunos pronunciamientos efectuados por la Corte Suprema de Justicia, lo cierto es que esta máxima corporación de la justicia ordinaria ha depurado una sólida línea jurisprudencial con relación a la vigencia de los reajustes pensionales de los que trata el artículo 21 del Decreto 758 (1990). 
En los fallos que se detallan a continuación la controversia ha estado centrada preferentemente en el problema de precisar si los incrementos pensionales gozan del atributo de imprescriptibilidad que le es inherente al derecho pensional. Esto ha tenido lugar, en mayor medida, dada la dificultad que plantea dilucidar si frente al beneficio de acrecentamiento pensional, es posible solicitar su reconocimiento pasado el término trienal del que trata el artículo 488 del Código Sustantivo del Trabajo (1951) y el artículo 151 del Código Procesal del Trabajo y de la Seguridad Social (1948), disposiciones que regulan la prescripción en materia laboral.

Es por lo anterior que desde hace un tiempo la Sala de Casación Laboral de la Corte Suprema de Justicia ha establecido que el beneficio de acrecentamiento pensional se encuentra vigente para aquellos jubilados que hayan adquirido el derecho en virtud del régimen de transición del que trata el artículo 36 de la Ley 100 (1993). De esta manera, quien cumple con los requisitos del régimen de transición es de igual forma beneficiario de los incrementos pensionales por encontrarse en la norma anterior bajo la cual se concedió la pensión, a saber, la del Acuerdo 049 (1990).

Es importante agregar que a ese mismo razonamiento se llega si se aplica el principio de inescindibilidad o conglobamiento de la ley laboral, el cual implica que, al momento de elegirse la norma más favorable, esta debe aplicarse en su totalidad, sin escindir su contenido. En cualquier caso, una de las primeras sentencias en donde la Corte tuvo la oportunidad de ocuparse del tema fue en el pronunciamiento del 27 de julio de 2005 (Sentencia 21517/05, 2005) con ponencia de la magistrada Isaura Vargas Díaz y el conjuez ponente Jaime Moreno García.

En aquella ocasión, la Corte Suprema de Justicia, actuando como juez de instancia, se ocupó de resolver el recurso de casación interpuesto por el ISS, contra la sentencia proferida por la Sala Laboral del Tribunal Superior del Distrito Judicial de Montería (Córdoba). Allí se conceptuó lo siguiente:

Es verdad que los incrementos de las pensiones no están involucrados en la mencionada Ley 100, pero ello no significa que pierdan su vigencia; por el contrario, si tal normatividad no los reguló, no quiere decir que los hubiera derogado, entonces en ese orden conservan su pleno vigor. (Sentencia 21517/05, 2005)

A esta conclusión se llegó luego de considerar que, ante la duda o conflicto sobre la vigencia de los incrementos de las pensiones, si bien el artículo 22 del Acuerdo 049 (1990) preceptúa que los incrementos de pensionales no hacen parte de la pensión de vejez o invalidez de origen común -monto-, por así haberlo dispuesto expresamente el legislador, no por ello sería dable argüir que el referido beneficio haya sido derogado tácitamente al haber entrado en vigor la Ley 100 (1993).

Esto se debe a que un razonamiento contrario, no promulgaría con los principios que auxilian la interpretación judicial en materia laboral y de seguridad social, a saber, 
los principios de favorabilidad e inescindibilidad que comporta el derecho al trabajo. Por otra parte, siguiendo con el derrotero trazado por la Sentencia 21517/05 (2005), en el año 2007 la Sala de Casación Laboral de la Corte Suprema de Justicia en la Sentencia 29741/07 (2007), con ponencia del Magistrado Luis Javier Osorio López, expresó sobre el tema en cuestión lo siguiente:

En este orden de ideas, al no disponer la Ley 100 de 1993 nada al respecto de los incrementos de marras, los cuales de acuerdo con lo atrás expresado no pugnan con la nueva legislación, es razonable concluir como lo hizo el ad quem, que dicho beneficio se mantiene en vigor; se insiste, para el afiliado que se le aplique por derecho propio o por transición el aludido Acuerdo 049 de 1990. (Sentencia 29741/17, 2007, p. 21)

A este razonamiento arribó la Corte Suprema de Justicia luego de considerar que no era dable afirmar que, frente al derecho de incremento pensional por familiar a cargo, había operado el fenómeno de la supresión o derogatoria expresa o tácita del que trata el artículo 71 y 72 del Código Civil colombiano. Así mismo, se hizo alusión a que el referido razonamiento encuentra respaldo en la protección reforzada que el constituyente de 1991 quiso brindarle al derecho al trabajo y a la seguridad social, conforme lo pregona los artículos 48 y 53 de la Constitución Política (1991).

Posteriormente, en la Sentencia 36345/10 (2010) del 10 de agosto, proferida con ocasión del recurso de casación interpuesto por el ISS, contra la sentencia proferida por el Tribunal Superior del Distrito Judicial de Medellín (Antioquia), con ponencia del Magistrado Francisco Javier Ricaurte Gómez, la Sala Laboral de la Corte Suprema de Justicia hizo uso de la técnica de reiteración de jurisprudencia. En este sentido, no entró a modificar la tesis jurídica establecida a partir de la Sentencia 21517/05 (2005) -sentencia fundadora de línea-. En esta ocasión, la Corte expresó lo siguiente:

Con todo, basta señalar que tiene razón la réplica al oponerse y que sobre el tema ya la Corte ha indicado que, en su sentir, los incrementos previstos por el artículo 21 del Acuerdo 049 de 1990, aprobado por el Decreto 758 del mismo año, conservan vigencia. Así, en sentencia de 5 de diciembre de 2007, al reiterarse la 21517 de 2005, se dijo. (Sentencia 36345/10, 2010, p. 189)

A esta conclusión arribó este tribunal, luego de realizar el análisis del segundo cargo formulado por el demandante dentro de aquel trámite de casación. En este se había argüido que el fallo del tribunal de alzada había sido violatorio en vía directa, en la modalidad de aplicación indebida del artículo 21 del Acuerdo 049 (1990) e interpretación errónea del artículo 31 de la Ley 100 (1993). No obstante, la Corte encontró que dicho cargo no tenía vocación de prosperidad por el motivo atrás referido.

Así mismo, para el año 2016, con ponencia del Magistrado Rigoberto Echeverri Bueno, en la Sentencia 53575/16 (2016) del 13 de julio, la Sala de Casación Laboral de la Corte Suprema de Justicia se reiteró el criterio jurisprudencial que se ha venido 
manejando al interior de dicha corporación de justicia, en lo atinente a la vigencia del beneficio de incremento pensional del que trata el Acuerdo 049 (1990) y el Decreto 758 (1990). En esta oportunidad, la Corte rememoró el criterio jurisprudencial de la vigencia de los incrementos pensionales por persona a cargo y expresó lo siguiente:

Ahora, aunque en las recordadas sentencias esta Corte avalo la vigencia del beneficio pensional por persona a cargo con posterioridad a la Ley 100 de 1993, en virtud de lo establecido en el artículo 31 de esa misma normativa, lo cierto es que el censor está realizando una interpretación tergiversada de lo allí consignado, en tanto al hacer alusión a tal precepto no se quiso dar a entender que ese auxilio pensional podía concederse a todos los pensionados, sino precisamente, dar soporte a su concepción, luego de expedida la Ley 100 de 1993, pero para aquellos afiliados cuya situación pensional la gobierna el Decreto 758 de 1990. (Sentencia 53575/16, 2016, pp. 28-29)

En este punto, es necesario, como lo manifestó la Corte Suprema, indicar que el auxilio económico adicional del que trata el Acuerdo 049 (1990) y su decreto aprobatorio, solo se es exigible por aquellos pensionados que se encuentran protegidos por dicha normatividad. De esta manera, no es exigible para aquellos jubilados a los que se le haya reconocido su pensión en virtud de reglamentos anteriores a la Ley 100. Por ejemplo, un jubilado al que se le haya otorgado su pensión en aplicación de la Ley 33 (1985) no es posible que entre a solicitar el referido beneficio, en tanto dicha postura pugnaría con el principio de inescindibilidad de la ley laboral.

Ulteriormente, la Corte Suprema de Justicia en la sentencia del 9 de mayo de 2018, con ponencia del Magistrado Gerardo Botero Zuluaga, en sede de revisión, se ocupó de la tarea de verificar si el cargo formulado por el promotor del recurso extraordinario, atinente a la vulneración del debido proceso y al principio de legalidad por haberse aplicado una norma derogada -artículo 21 del Decreto 758 (1990)- tenía vocación de prosperidad. No obstante, al encontrar la Corte que las afirmaciones realizadas por el censor no poseían el peso suficiente para revocar el fallo censurado, la Corte se sirvió conceptuar que tales acrecentamientos, aún después de expedida la Ley 100 (1993), se encuentran vigentes y en esa medida no se vislumbraba violación alguna a los referidos derechos. Por ello, la Corte actuando como tribunal de revisión, expresó lo siguiente:

En efecto, en torno al aspecto referido en precedencia, ya esta Corporación en forma reiterada y constante ha fijado su línea de pensamiento sobre la viabilidad y procedencia de los incrementos pensionales por persona a cargo, aún después de la promulgación de la Ley 100 de 1993, por aplicación del régimen de transición previsto en el artículo 36 de la referida ley, para lo cual puede consultarse las sentencias CSJ SL, 27 jul. 2005, rad. 21517, CSJ SL, 5 dic. 2007, rad. 29741, reiterada en CSJ SL, 10 ag. 2010, rad. 36345. (Sentencia 51706/18, 2018, p. 11)

Finalmente, en la sentencia del 11 de junio de 2019, con ponencia del Magistrado Santander Rafael Brito Cuadrado, en sede del Tribunal de Casación, la Corte Suprema de Justicia entró a revocar la sentencia dictada el 5 de diciembre de 2012 por el Tribunal 
Superior del Distrito Judicial de Pereira (Risaralda), al encontrar equivocado el razonamiento efectuado por el ad quem dentro del aludido proceso. En esta oportunidad, la Corte señaló lo siguiente:

Sobre la vigencia de los incrementos por persona a cargo, la jurisprudencia ha definido que es viable reconocerlos, aun con posterioridad a la entrada en vigor de la Ley 100 de 1993, como en el fondo lo sostiene la censura; así lo ha contemplado pero en favor de los pensionados a quienes se le reconoció la prestación económica directamente, en aplicación del Acuerdo 049 de 1990 o con ocasión del régimen de transición del artículo 36 de la Ley 100 de 1993, condiciones que acredita el recurrente, en razón a que no se discute la fuente normativa de la pensión que recibe. (Sentencia 60910/19, 2019, p. 32)

De todo lo anterior, se desprende que la Corte Suprema de Justicia, en ejercicio de las funciones atribuidas por la constituyente de 1991 en el artículo 234 constitucional -de unificar jurisprudencia-, desde el año 2005 ha sentado una línea jurisprudencial inequívoca respecto a la vigencia de los incrementos pensionales por persona a cargo.

Esta línea es aplicable como lo ha reiterado la propia Corte, solo para aquel pensionado que haya accedido a la mesada en aplicación directa del Acuerdo 049 (1990), o se encuentre bajo el resguardo del régimen de transición previsto por el artículo 36 de la Ley 100 (1993), siempre y cuando perduren las causas que dan origen a la reclamación de tal derecho.

\section{JURISPRUDENCIA DE LA CORTE CONSTITUCIONAL}

Antes de entrar a describir los principales pronunciamientos que ha proferido la Corte Constitucional de Colombia en lo atinente al estudio de la prerrogativa de incremento pensional por familiar a cargo, es necesario hacer una advertencia, a modo de preámbulo del referido estudio. Esta alta corporación de la justicia constitucional ha consolidado a través de sus salas de revisión dos posturas divergentes entre sí, a saber, una línea jurisprudencial que identifica y respalda la tesis de la imprescriptibilidad de los incrementos pensionales, y la otra que se equipara a la cimentada por la Corte Suprema de Justicia.

Esta última postura ha sido defendida por la Sala Segunda y Tercera de Revisión, en las cuales se ha señalado que los beneficios de incremento pensional sí son susceptibles del fenómeno jurídico de la prescripción, al no formar parte integral de la pensión. Por tal motivo, no participan de los atributos y ventajas que el legislador ha señalado para la pensión.

De esta manera, como es posible advertir, jurisprudencialmente se ha señalado reiteradamente que la calidad de pensionado es permanente y vitalicia conforme al articulado constitucional. No obstante, las mesadas pensionales, por ser prestaciones periódicas, son susceptibles de la prescripción extintiva si no se reclaman dentro del 
término trienal dispuesto por el legislador. Esta misma tesis jurídica es aplicada mutatis mutandis frente al derecho de incremento pensional por persona a cargo.

De acuerdo con lo anterior, como es de suponerse, el análisis de la imprescriptibilidad o prescriptibilidad de los incrementos pensionales por familiar a cargo, realizado por la Corte Constitucional de Colombia en el último decenio, ha partido inevitablemente de la base fundamental de que los incrementos pensionales se encuentran vigentes. Esto se debe a que no se puede predicar la ocurrencia de dicho fenómeno en un derecho que no se encuentra en vigor.

De este modo, la Corte Constitucional si bien desde un principio no ha tratado como ratio decidendi el tema de la vigencia de los incrementos pensionales, sí se ha sostenido la tesis mayoritaria que los mismos no prescriben. De esto se desprende que, implícitamente, sí se estaba reconociendo la vigencia de los incrementos aún después de la promulgación de la Ley 100 (1993).

Pero solo frente a quienes se le había reconocido la pensión con base en el Acuerdo 049 (1990) y el Decreto 758 (1990). Sin embargo, la Corte Constitucional, de manera aterradora, con una sentencia equivocada, pasa de una tesis intermedia a una tesis restrictiva de los incrementos pensionales por familiar a cargo, con la Sentencia SU140/19 (2019).

Por lo anterior, en el siguiente recuadro (tabla 1) se ejemplifica los principales pronunciamientos emanados por la Corte Constitucional de Colombia antes de haberse proferido la Sentencia SU-310/17 (2017), que fue anulada en su momento por el Auto 320 (2018). Esto se hizo, porque a juicio del criterio mayoritario de la Sala Plena de la Corte Constitucional de Colombia, en el referido trámite se había incurrido en la causal de nulidad designada como "omisión arbitraria, de analizar asuntos de relevancia constitucional que tienen efectos trascendentales para el sentido de la decisión" (Auto 320/18, 2018).

Lo anterior tuvo lugar porque la Corte Constitucional encontró que, en el juicio aludido, se había dejado de examinar los argumentos propuestos por la Administradora Colombiana de Pensiones (Colpensiones), y el Ministerio de Hacienda y Crédito Público. Los referidos cuestionamientos giraban en torno a la omisión, entre otras razones, del estudio del criterio orientador del gasto público social, principio o directriz de sostenibilidad financiera, que se encuentra implícito en varias cláusulas constitucionales. Por ejemplo, en el artículo 334 de la Carta Política.

No obstante, es menester indicar que la pauta hermenéutica anterior fue incorporada puntualmente en el artículo 48 constitucional, a partir de la reforma constitucional introducida por intermedio del Acto Legislativo 01 (2005), el cual eleva a rango constitucional, el principio de sostenibilidad financiera en materia de seguridad social. 
Por otra parte, es preciso manifestar que la referida causal de nulidad ha sido desarrollada mediante el Auto 223 (2006). De esta forma, la Sentencia SU-310/17 (2017) fue remplazada mediante la Sentencia SU-140/19 (2019), en donde se adoptó la tesis de la derogatoria orgánica, hoy por hoy tan discutida.

Tabla 1. Prescripción incrementos pensionales

\begin{tabular}{cc}
\hline Tesis de la prescriptibilidad & Tesis de la imprescriptibilidad \\
\hline T-791/2013 & T-217/2013 \\
T-748/2014 & T-831/2014 \\
T-123/2015 & T-319/2015 \\
T-541/2015 & T-369/2015 \\
T-038/2016 & T-140/2016 \\
& T-395/2016 \\
\hline
\end{tabular}

Fuente: Santander (s.f.)

De acuerdo con lo anterior, para el estudio del primer pronunciamiento expresado por nuestro tribunal constitucional en la materia nos debemos remitir al 17 de abril del año 2013. En este año, con ponencia del Magistrado Alexei Julio Estrada, la Corte Constitucional tomó para revisión dos acciones de tutela promovidas ante la Sala de Casación Laboral de la Corte Suprema de Justicia, que fueron negadas en primera y segunda instancia. Estas acciones de tutela iban dirigidas contra el Juzgado Cuarto Laboral del Circuito de Barranquilla y la Sala Laboral del Tribunal Superior del mismo distrito judicial.

En aquella oportunidad, ambos despachos judiciales en sede de primera y segunda instancia, dentro del proceso ordinario laboral primigenio, absolvieron a Colpensiones de las pretensiones formuladas en su contra. Esto se dio gracias que se pudo probar la excepción de prescripción frente al derecho de incremento pensional por persona a cargo que había sido formulada por Colpensiones.

En razón a lo anterior, en el referido trámite constitucional, la Corte se ocupó de la tarea de verificar si en los mentados casos se había configurado la causal específica de procedibilidad de la acción de tutela contra providencia judicial. Esta fue llamada "defecto sustantivo por desconocimiento del precedente judicial" (Sentencia T-217/13, 2013). La Corte encontró que, efectivamente, las autoridades judiciales encargadas habían desconocido el precedente jurisprudencial sentado en la materia, y en esta línea se concluyó lo siguiente:

la Sala observa que las sentencias recurridas incurren un defecto sustantivo por desconocimiento del precedente jurisprudencial establecido por la Corte Constitucional, el cual estipula que el término de prescripción es predicable únicamente de las mesadas pensionales no reclamadas y deducido del contenido 
de las prestaciones, razón por la cual estima la Sala que en los casos analizados, dar aplicación a los artículos 488 del Código Sustantivo del Trabajo y 151 del Código Procesal del Trabajo y de la Seguridad Social, constituye una decisión que vulnera directamente los principios de eficiencia, universalidad y solidaridad con sujeción a los cuales el Estado tiene la obligación de prestar el servicio público de la seguridad social. (Sentencia T-217/13, 2013)

Este pronunciamiento es una sentencia fundadora de línea, en tanto su ratio decidendi ha sido seguida, en mayor o menor medida, en las sentencias T-831/14 (2014), T-319/15 (2015), T-369/15 (2015), T-140/16 (2016), y T-395/16 (2016). En esta última, se afirmó que la Sentencia T-217/13 (2013) no establece un precedente constitucional de obligatorio acatamiento, ya que, para aquel momento y como persiste en la actualidad, no existe una postura unánime en la materia.

Por esta razón, al no existir un criterio uniforme e inequívoco, no era dable invocar dicha causal de procedibilidad para la acción de tutela. No obstante, en el referido proceso se decidió tutelar las súplicas deprecadas por los tutelantes, pero por una causal distinta a la invocada. Esta vez por la causal específica descrita como violación directa de la Constitución Política. De esta manera, se probó la no aplicación del principio de favorabilidad laboral para el reconocimiento y pago del incremento por persona a cargo.

Del mismo modo, la Corte Constitucional, entre sus salas segunda y tercera de revisión, ha desarrollada la tesis de la prescriptibilidad de los incrementos pensionales. Para lo anterior ha hecho uso de la doctrina creada por la Corte Suprema de Justicia, en donde se ha señalado que los susodichos reajustes pensionales pueden ser objeto de prescripción si su reclamación no se realiza dentro del término de tres años dispuestos por el legislador. Esto tanto en el artículo 488 del Código Sustantivo del Trabajo, como en el artículo 151 del Código Procesal del Trabajo.

Dicho criterio jurisprudencial, ha sido defendido, entre otras sentencias, en la Sentencia T-791/13 (2013), en donde la Corte Constitucional, conoció del proceso constitucional iniciado por el ciudadano Carlos Arnulfo Sánchez Pineda, en contra de la Sala Laboral del Tribunal Superior del Distrito Judicial de Bogotá (Cundinamarca). Este mecanismo de acción de amparo fue promovido ante la Corte Suprema de Justicia.

Este órgano en su Sala de Casación Laboral y Penal, en primera y segunda instancia respectivamente, encontró no próspera la acción incoada por no avizorar vulneración a derecho fundamental alguno. En particular, por el vedo que recae sobre el juez constitucional de inmiscuirse en asuntos que son de competencias de los jueces ordinarios.

No obstante, la Corte Constitucional, en cumplimiento de las competencias asignadas por el Decreto 2591 (1991), tomó para revisión el referido caso. Allí encontró que no era viable otorgar el amparo solicitado por el accionante, ya que el actor había 
solicitado el reajuste pensional al cabo de quince años de habérsele reconocido la pensión. Además, se probó que su consorte dependía económicamente de él, pero desde hace aproximadamente veinte años atrás para aquel momento. Por ello en aquella ocasión la Corte concluyó lo siguiente:

Por otro lado, el incremento pensional del 14 \% por cónyuge o compañera(o) permanente a cargo que pretende el señor Sánchez Pineda, tal y como la jurisprudencia de la Corte Suprema de Justicia lo ha adoctrinado, no reviste un carácter fundamental, esencial o vital, toda vez que no va dirigido, de forma vitalicia y sucesiva, a amparar la subsistencia digna y sufragar el mínimo vital del actor, quien por una contingencia sufrida (la vejez), vio menguada de forma permanente su capacidad de sostenimiento. Esto, por cuanto dicho incremento, es un derecho patrimonial, que no forma parte integrante de la pensión que recibe el accionante, y que está condicionado al cumplimiento de unos requisitos subsidiarios y ajenos a la contingencia de vejez, que es la que se busca amparar a través del derecho fundamental a la seguridad social. (Sentencia T-791/13, 2013, pp. 19-20)

A esta conclusión llegó la Corte luego de encontrar que el derecho al acrecentamiento pensional no es una prerrogativa de aquellas destinadas a garantizar la subsistencia digna o el mínimo vital de las personas, ya que su falta reconocimiento no afecta el sostenimiento del jubilado.

En este punto es necesario realizar un reparo a la sentencia en estudio, ya que eventualmente podría argüirse que no resulta proporcionado que a la luz de los principios de universalidad y solidaridad que guían el Sistema General de Seguridad Social en pensiones, se entre a realizar una interpretación restrictiva que comprime el derecho a una pensión a una mínima expresión.

Esto se debe a que el derecho a una pensión mínima, vital y móvil se vería reducido sustancialmente, al no reconocerse la prestación económica en un monto que se ajuste a las condiciones reales del pensionado. Sobre todo, si se tiene en cuenta que, como lo manifestó en su momento el Magistrado Gerardo Botero Zuluaga, en el salvamento de voto realizado a la sentencia del 18 de marzo de 2020 "una pensión deficitaria no cumple su propósito de garantizar una renta vitalicia digna y proporcional a las necesidades propias del beneficiario y de su núcleo familiar" (Sentencia 59026/20, 2020).

Finalmente, la Corte Constitucional, en una sentencia aislada, se ocupó de la tarea de analizar la vigencia de la prerrogativa consagrada en el artículo 21 del Decreto 758 (1990). De esta manera, con ponencia del Magistrado Antonio José Lizarazo Ocampo, en sede de revisión, profirió la Sentencia T-456/18 (2018).

En aquella ocasión, la Corte tomó para revisión once solicitudes de acción de amparo que había conocido de manera previa la Corte Suprema de Justicia. Sin embargo, estas habían sido resultas de manera adversa a los intereses de los accionantes, al no encontrarlas arbitrarias o configurativas de vía de hecho alguna, con respecto a las decisiones de instancia tomadas dentro de los respectivos procesos ordinarios laborales. 
En dicha sentencia, la Corte Constitucional centró su atención en corroborar la vigencia de los artículos 21 y 22 del Acuerdo 049 (1990), luego de haberse promulgado la Ley 100 (1993). En este sentido, se señaló que, dada la naturaleza accesoria y temporal del beneficio de incremento pensional por familiar a cargo, no era dable señalar que el referido beneficio hubiese mantenido vigor luego de expedida la Ley 100. Ya que, por no hacer parte del monto de la pensión, no era susceptible del fenómeno de la ultractividad de la ley, por virtud del régimen de transición pensional del artículo 36 de la Ley 100 (1993).

De igual forma, se hizo alusión a la modificación introducida en el artículo 48 constitucional por intermedio del Acto Legislativo 01 (2005), luego de incorporarse la regla según la cual, toda pensión debe ser liquidada conforme a lo efectivamente cotizado por el afiliado.

Este canon constitucional presuntamente se trasgrediría al aceptarse el reconocimiento y pago de los mencionados aumentos pensionales. Pues en efecto, el solo hecho de encontrarse en unión conyugal y marital, o en convivencia y dependencia de hijo no origina cotización alguna.

Adicionalmente, la Corte Constitucional manifestó que tampoco era predicable alegar la vulneración del precedente de imprescriptibilidad de los derechos sociales, sobre una prerrogativa derogada tácitamente y que, en todo caso, no era considerada legalmente como un derecho integrante de la pensión de vejez.

En definitiva, la referida sentencia fue el boceto de lo que luego vino a representar la Sentencia SU-140/19 (2019). Por cuanto, para aquella ocasión, la Sala Quinta de Revisión de Tutela, estuvo integrada por los Magistrados Antonio José Lizarazo Gómez, Gloria Ortíz Delgado - quien realizo salvamento de voto-y Cristina Pardo Schlesinger. Esta última fue a su vez la Magistrada ponente de la Sentencia SU-140/19 (2019) y del Auto 320 (2018), este último anulatorio de la Sentencia SU-310/17 (2017).

\section{ALCANCES Y LÍMITES DE LA SENTENCIA SU-140 DE 2019}

Inicialmente, resulta oportuno mencionar que en el pronunciamiento de unificación SU-140 (2019) cuatro Magistrados salvaron su voto frente a la decisión finalmente adoptada por la Sala Plena de la Corte Constitucional. Estos mismos togados salvaron su voto en el Auto 320 (2018), lo que deja entrever que aún no existe unanimidad en dicho Tribunal de Justicia frente a la vigencia de los incrementos pensionales por persona a cargo.

Dicho acontecer también se ha hecho notar en algunos tribunales superiores del país. Ejemplo de lo anterior es la decisión adoptada mediante la sentencia del 25 de septiembre de 2019, con ponencia de la Magistrada María Matilde Trejos Aguilar, en donde el Tribunal Superior del Distrito Judicial de Guadalajara de Buga (Valle del Cauca) 
se acogió, con relación a la vigencia y prescripción de los incrementos pensionales por familiar a cargo, el criterio jurisprudencial edificado por la Sala Laboral de la Corte Suprema de Justicia, y se descartó lo sostenido por la Corte Constitucional mediante Sentencia SU-140/19 (2019).

Bajo esta óptica, conviene advertir que si bien el artículo 230 constitucional (1991), preceptúa que los jueces en sus providencias están sometidos al imperio de la ley', lo cierto es que dicho mandato de acatamiento del precedente no puede verse como una camisa de fuerza que limite la autonomía e independencia del operador jurídico.

Ya que tanto constitucional y como legalmente es viable que el operador judicial se aparte de un precedente jurisprudencial sentado por un tribunal de cierre, lo anterior siempre y cuando concurran determinados eventos. Para ello, en la Sentencia C-621/15 (2015) la Corte Constitucional conceptúo lo siguiente:

Según lo establecido en su larga jurisprudencia por este tribunal, una vez identificada la jurisprudencia aplicable al caso, la autoridad judicial solo puede apartarse de la misma mediante un proceso expreso de contra-argumentación que explique las razones del apartamiento, bien por: (i) ausencia de identidad fáctica, que impide aplicar el precedente al caso concreto; (ii) desacuerdo con las interpretaciones normativas realizadas en la decisión precedente; (iii) discrepancia con la regla de derecho que constituye la línea jurisprudencial. De este modo, la posibilidad de apartamiento del precedente emanado de las corporaciones judiciales de cierre de las respectivas jurisdicciones supone, en primer término, un deber de reconocimiento del mismo y, adicionalmente, de explicitación de las razones de su desconsideración en el caso que se juzga. (Sentencia C-621/15, 2015)

La citada regla jurisprudencial guarda sintonía con lo señalado en la Sentencia T-309/15 (2015). Allí la Corte indicó que a fin de hacer efectivo el derecho a la igualdad de los ciudadanos que acceden a la administración de justicia, pero sin perder de vista la autonomía e independencia judicial de la que goza el operador judicial, para que un apartamiento sea considerado válido se debe cumplir con los siguientes requisitos.

En primer lugar, transparencia, en palabras de la Corte esta exigencia supone que el juez reconoce la regla del derecho aplicable al caso en concreto, y en tal sentido, hace explícito en el contenido de la sentencia el precedente conforme al cual sus superiores funcionales o su propio despacho, han resuelto casos análogos o similares al objeto de litis.

Así mismo, para que dicho apartamiento del precedente no sea tildado como constitutivo de vía de hecho, el operador judicial debe acreditar, en segundo lugar, la suficiencia argumentativa, requisito conforme al cual, se le exige al juez exponer

Entiendo por ley al conjunto de normas constitucionales y legales incluyendo la hermenéutica jurisprudencial de los máximos órganos de cierre de las jurisdicciones, especialmente de la ordinaria y constitucional; tal y como pacíficamente lo ha enseñado la misma jurisprudencia de la Corte Constitucional de Colombia. 
razones suficientes y válidas a la luz del ordenamiento jurídico y los supuestos fácticos que justifiquen el cambio jurisprudencial.

Bajo este entendido, para la Corte Constitucional, como fue compendiado en la Sentencia C-621/15 (2015), no resulta suficiente que el funcionario limite su labor únicamente a expresar argumentos en otro sentido, sino que es imperativo que en el cuerpo de la sentencia quede demostrado por qué el precedente anterior no resultaba válido, correcto o suficiente para resolver el caso nuevo. En últimas, se trata que el juez esgrima razones de por qué su providencia se constituye en mejor respuesta al problema jurídico llevado a la judicatura.

Por otra parte, como se puso de presente en el salvamento de voto registrado por el Magistrado José Fernando Reyes Cuartas, en la Sentencia SU-140/19 (2019), no es evidente la derogatoria orgánica de la que pregona esta sentencia. Ya que tal declaración se hizo en sede de control concreto de constitucionalidad o control difuso, como suele nombrarse comúnmente en la doctrina constitucional, y no en sede de control abstracto, en donde los efectos son erga omnes. De esta manera, por ser una sentencia de unificación, por mandato expreso del legislador, sus efectos son inter partes y no constituyen una ratio decidendi que obligue a los operadores jurídicos.

Finalmente, otro aspecto para tener en cuenta es que, frente a dos posiciones jurisprudenciales divergentes entre sí, es válido que los jueces ordinarios continúen acogiendo la tesis planteada por la Corte Suprema, ya que se trata de una posición uniforme contenida en más de tres decisiones de la Corte Suprema de Justicia como tribunal de cierre.

Estas posiciones son, por un lado, la planteada por el órgano de cierre de la jurisdicción ordinaria, a partir de la sentencia del 27 de julio de 2005, postura que se ha mantenido a lo largo de los años. Por otro lado, el nuevo criterio sentado por la Corte Constitucional de Colombia, con ocasión de la Sentencia SU-140/19 (2019). De esta manera, conforme al artículo 4 de la Ley 169 (1896), se constituye en una doctrina probable, que en palabras de la Corte Constitucional la institución mencionada consiste en lo siguiente:

La doctrina legal, probable o jurisprudencia constante, es propia de los sistemas jurídicos legalistas o mejor conocidos como civil law, en donde la jurisprudencia es considerada una fuente auxiliar pues no tiene la capacidad de generar obligaciones generales y abstractas, sino que se limita a interpretar la ley en su aplicación, y dicha interpretación tiene un mayor o menor grado de autoridad, pero exclusivamente frente a los jueces de menor jerarquía en sus decisiones y no como normas obligatorias para la administración en general. (Sentencia C-621/15, 2015)

La referida técnica de interpretación encuentra respaldo en el artículo 4 de la Ley 169 (1896). En este se afirma que tres decisiones uniformes, proferidas por la Corte 
Suprema de Justicia como Tribunal de Casación, sobre un mismo problema de derecho, conforman una doctrina probable.

En este sentido, los operadores judiciales podrán aplicarla en casos análogos o semejantes. Disposición que fue declarada exequible por la Corte Constitucional de Colombia en Sentencia C-836/01 (2001). Así, pese a su antigüedad, se encuentra en plena vigencia.

\section{CONCLUSIONES}

La Sentencia SU-140/19 (2019) parte de un equívoco constitucional al considerar, en primer lugar, que la sostenibilidad fiscal es un principio y, en segundo lugar, que ante el conflicto entre la regla de sostenibilidad financiera y el principio de primacía de los derechos inalienables de la persona, el segundo debe ceder frente al primero. De esta manera, se obstaculiza el mandato establecido en el artículo 334 constitucional, el cual preceptúa que ninguna autoridad pública podrá invocar la sostenibilidad fiscal para socavar derechos fundamentales, restringir su alcance, o negar su protección efectiva.

Con el Auto 320 (2018) se socaba el principio de seguridad jurídica que gobierna los procesos constitucionales. En este sentido, se permite que, en cada caso, se redefina las causales de anulabilidad desarrolladas por la misma jurisprudencia constitucional, y deja a merced de cada operador judicial establecer cuándo se está en presencia o no de la causal descrita como "omisión arbitraria de asuntos de relevancia constitucional que tienen efectos trascendentales para el sentido de la decisión" (Auto 320/18, 2018). Así mismo, se podría argüir que, en el peor de los escenarios trazados, se crea en perjuicio de la clase trabajadora, y de la ciudadanía del común, una nueva causal autónoma de anulabilidad de las sentencias, "la omisión del estudio del impacto financiero de las medidas de protección de derechos fundamentales" (Auto 320/18, 2018).

A través de la Sentencia SU-140/19 (2019), sobre un manto de legalidad, se elimina ingeniosamente la postura más defendida entre las salas de revisión, esto es, la tesis de la imprescriptibilidad de los incrementos pensionales. Ya que al no poder eludir dicha protección garantista fundamentada en la aplicación del principio de favorabilidad laboral o in dubio pro operario, se prefiere llevar el debate a otro plano, esta vez al económico. En pocas palabras, se integra un nuevo criterio para definir el alcance de un derecho fundamental, contrariando de esta forma, el mandato del artículo 334 constitucional, el cual manifiesta que bajo ninguna circunstancia una autoridad pública podrá invocar la sostenibilidad fiscal para menoscabar, restringir o negar el alcance de los derechos fundamentales. 


\section{REFERENCIAS}

Arrieta, C. (2011). Las reformas del sistema pensional colombiano. [Artículo en línea]. https://library. fes.de/pdf-files/bueros/kolumbien/08859.pdf

Asamblea Nacional Constituyente (1991, 20 de julio). Constitución Política de Colombia. Gaceta Constitucional 116. http://www.secretariasenado.gov.co/senado/basedoc/constitucion_ politica_1991.html

Congreso de la República (1948, 24 de junio). Decreto Ley 2158 de 1948. Código Procesal del Trabajo y de la Seguridad Social. http://www.secretariasenado.gov.co/senado/basedoc/codigo_procedimental_ laboral.html

Congreso de la República de Colombia (1951, 7 de junio). Decreto Ley 3743 de 1950. Código Sustantivo del Trabajo. http://www.secretariasenado.gov.co/senado/basedoc/codigo_sustantivo_trabajo.html

Congreso de la República de Colombia (1972, 30 de diciembre). Ley 16 de 1972. Por medio de la cual se aprueba la Convención Americana sobre Derechos Humanos "Pacto de San José de Costa Rica", firmado en San José, Costa Rica el 22 de noviembre de 1969. Diario Oficial n. 33.780. http://www.suin-juriscol.gov.co/ viewDocument.asp?ruta $=$ Leyes $/ 1572401$

Congreso de la República de Colombia (1985, 29 de enero). Ley 33 de 1985. Por la cual se dictan algunas medidas en relación con las Cajas de Previsión y con las prestaciones sociales para el Sector Público. https:// www.funcionpublica.gov.co/eva/gestornormativo/norma.php?i $=248$

Congreso de la República de Colombia (1988, 19 de diciembre). Ley 71 de 1988. Por la cual se expiden normas sobre pensiones y se dictan otras disposiciones. https://www.funcionpublica.gov.co/eva/gestornormativo/ norma.php?i $=307$

Congreso de la República de Colombia (1992, 18 de mayo). Ley 4 de 1992. Mediante la cual se señalan las normas, objetivos y criterios que debe observar el Gobierno Nacional para la fijación del régimen salarial y prestacional de los empleados públicos, de los miembros del Congreso Nacional y de la Fuerza Pública y para la fijación de las prestaciones sociales de los Trabajadores Oficiales y se dictan otras disposiciones, de conformidad con lo establecido en el artículo 150, numeral 19, literales e) y f) de la Constitución Política. https://www. funcionpublica.gov.co/eva/gestornormativo/norma.php?i=1166

Congreso de la República de Colombia (1993, 23 diciembre). Ley 100 de 1993. Por la cual se crea el sistema de seguridad social integral y se dictan otras disposiciones. Diario Oficial n..$^{\circ}$ 41.148. http://www. secretariasenado.gov.co/senado/basedoc/ley_0100_1993.html

Congreso de la República de Colombia (1996, 7 de marzo). Ley 270 de 1996. Estatutaria de la Administración de Justicia. Diario Oficial n. ${ }^{\circ}$ 42.745. http://www.secretariasenado.gov.co/senado/basedoc/ ley_0270_1996.html

Congreso de la República de Colombia (2005, 22 de julio). Acto Legislativo 01 de 2005. Por el cual se adiciona el artículo 48 de la Constitución Política. Diario Oficial n. ${ }^{\circ}$ 45.980. http://www. secretariasenado.gov.co/senado/basedoc/acto_legislativo_01_2005.html

Congreso de los Estados Unidos de Colombia. (1873, 26 de mayo). Ley 84 de 1873. Código civil de los Estados Unidos de Colombia. Diario Oficial n. ${ }^{\circ}$ 2.867. http://www.secretariasenado.gov.co/senado/ basedoc/codigo_civil.html

Consejo de Estado (2016, 25 de febrero). Sentencia 4683-13/16 (Gerardo Arenas Monsalve, C. P.). https://jurisprudencia.ramajudicial.gov.co/WebRelatoria/ce/index.xhtml 
Consejo de Estado (2017, 16 de noviembre). Sentencia 2741-08/17 (Gabriel Valbuena Hernández, C. P.). https://jurisprudencia.ramajudicial.gov.co/WebRelatoria/ce/index.xhtml

Consejo Nacional Legislativo (1887, 24 de agosto). Ley 153 de 1887. Que adiciona y reforma los Códigos nacionales, la ley 61 de 1886 y la 57 de 1887. Diario Oficial n. 7151 . http://www.suin-juriscol.gov.co/ viewDocument.asp?ruta $=$ Leyes $/ 1792950$

Corte Constitucional (2001, 8 de agosto). Sentencia C-831/01 (Álvaro Tafur Galvis, M. P.). https://www. corteconstitucional.gov.co/relatoria/2001/c-831-01.htm

Corte Constitucional (2002, 24 de septiembre). Sentencia C-789/02 (Rodrigo Escobar Gil, M. P.). https:// www.corteconstitucional.gov.co/RELATORIA/2002/C-789-02.htm

Corte Constitucional (2004, 10 de agosto). Sentencia C-754/04 (Álvaro Tafur Galvis, M. P.). https:// www.corteconstitucional.gov.co/relatoria/2004/C-754-04.htm

Corte Constitucional (2004, 19 de febrero). Sentencia C-131/04 (Clara Inés Vargas Hernández, M. P.). https://www.corteconstitucional.gov.co/relatoria/2004/c-131 -04.htm

Corte Constitucional (2006, 16 de agosto). Auto 223/06 (Jaime Córdoba Triviño, M. P.). https://www. corteconstitucional.gov.co/relatoria/Autos/2006/A223-06.htm

Corte Constitucional (2013, 12 de noviembre). Sentencia T-791/13 (Luis Guillermo Guerrero Pérez, M. P.). https://www.corteconstitucional.gov.co/relatoria/2013/T-791-13.htm

Corte Constitucional (2013, 17 de abril) Sentencia T-217/13 (Alexei Julio Estrada, M. P). https://www. corteconstitucional.gov.co/RELATORIA/2013/T-217-13.htm

Corte Constitucional (2015, 18 de junio). Sentencia T-369/15 (Jorge Ignacio Pretelt Chaljub, M. P). https://www.corteconstitucional.gov.co/relatoria/2015/t-369-15.htm

Corte Constitucional (2015, 22 de mayo) Sentencia T-309/2015 (Jorge Ignacio Pretelt Chaljub, M. P.). https://www.corteconstitucional.gov.co/relatoria/2015/T-309-15.htm

Corte Constitucional (2015, 22 de mayo). Sentencia T-319/15 (Gloria Stella Ortíz Delgado, M. P.). https:// www.corteconstitucional.gov.co/relatoria/2015/T-319-15.htm

Corte Constitucional (2016, 18 de marzo). Sentencia T-140/16. (Jorge Iván Palacio Palacio, M. P.). https:// www.corteconstitucional.gov.co/Relatoria/2016/T-140-16.htm

Corte Constitucional (2016, 28 de julio). Sentencia T-395/16 (Alejandro Linares Cantillo, M. P.). https:// www.corteconstitucional.gov.co/relatoria/2016/t-395-16.htm

Corte Constitucional (2016, 30 de septiembre). Sentencia C-621/15 (Jorge Ignacio Pretelt Chaljub, M. P.). https://www.corteconstitucional.gov.co/relatoria/2015/C-621-15.htm

Corte Constitucional (2016, 9 de marzo). Auto 111/16 (Jorge Ignacio Pretelt Chaljub, M. P.). https://www. corteconstitucional.gov.co/relatoria/autos/2016/a111-16.htm

Corte Constitucional (2017, 10 de mayo). Sentencia de unificación SU-310/2017. (Aquiles Arrieta Gómez, M. P.). https://www.corteconstitucional.gov.co/relatoria/2017/SU310-17.htm

Corte Constitucional (2017, 26 de enero). Auto 020/17 (Gabriel Eduardo Mendoza Martelo, M. P.). https://www.corteconstitucional.gov.co/relatoria/autos/2017/A020-17.htm

Corte Constitucional (2018, 23 de mayo). Auto 320/18. (Cristina Pardo Schlesinger, M. P.). https://www. corteconstitucional.gov.co/relatoria/autos/2018/a320-18.htm 
Corte Constitucional (2018, 27 de noviembre). Sentencia T-456/18 (Antonio José Lizarazo Ocampo, M. P.). https://www.corteconstitucional.gov.co/relatoria/2018/t-456-18.htm

Corte Constitucional (2019, 28 de marzo). Sentencia SU-140/19 (Cristina Pardo Schlesinger, M. P.). https://www.corteconstitucional.gov.co/relatoria/2019/SU140-19.htm

Corte Suprema de Justicia (1986, 26 de mayo). Sentencia 0052/86 (Manuel Enrique Daza Álvarez, M. P.).

Corte Suprema de Justicia (2005, 27 de julio). Sentencia 21517 (Isaura Vargas Díaz y Jaime Moreno García, M. P.).

Corte Suprema de Justicia (2007, 5 de noviembre). Sentencia 29741/07 (Luis Javier Osorio López, M. P.).

Corte Suprema de Justicia (2010, 10 de agosto). Sentencia 36345/10 (Francisco Javier Ricaurte Gómez, M. P.).

Corte Suprema de Justicia (2016, 13 de julio). Sentencia 53575/16 (Rigoberto Echeverri Bueno, M. P.).

Corte Suprema de Justicia (2018, 9 de mayo). Sentencia 51706/18 (Gerardo Botero Zuluaga, M. P.).

Corte Suprema de Justicia (2019, 11 de junio). Sentencia 60910/19 (Santander Rafael Brito Cuadrado, M. P.).

Corte Suprema de Justicia (2019, 13 de noviembre). Sentencia 57644/19 (Fernando Castillo Cadena, M. P.).

Corte Suprema de Justicia (2020, 18 de marzo). Sentencia 59026/20 (Clara Cecilia Dueñas Quevedo, M. P.).

Courtis, C., Parra, O., Rossi, J., Sepúlveda, M., Arango, R., Campos L., Kletzel, G., González, O., Mujica, J., Opie, J., Pisarello, G., Wolfgang, I., y Suárez, A. (2006). Ni un paso atrás: la prohibición de regresividad en materia de derechos sociales (Cristian Courtis, comp.). Editores del Puerto s.r.l. https://www.civilisac. org/civilis/wp-content/uploads/Ni-un-paso-atr\%C3\%Als-Cristian-Courtis.pdf

Duque, N., y Duque, S. (2016, enero-junio). El derecho fundamental a una pensión y el principio de sostenibilidad financiera: un análisis desde el régimen de prima media con prestación definida en Colombia. Justicia Juris, 12(1), 40-55. https://doi.org/10.15665/rj.v12i1.886

Espinosa, J. G. (2020). Análisis normativo de las medidas laborales y de seguridad social expedidas por el gobierno colombiano frente a la pandemia de la COVID-19: una mirada desde el principio de progresividad y no regresividad en los derechos sociales. [Tesis de grado, no publicada, Universidad de la Amazonia].

Fedesarrollo (2010). El sistema pensional en Colombia: retos y alternativas para aumentar la cobertura IInforme finall. https://www.repository.fedesarrollo.org.co/bitstream/handle/1 1445/351/El\%20sistema\%20 pensional\%20en\%20Colombia.pdf?sequence $=1$ EisAllowed $=y$

Ministerio de Defensa Nacional (1988, 29 de diciembre). Decreto 2701 de 1988. Por el cual se reforma el régimen prestacional de los empleados públicos y trabajadores oficiales de las entidades descentralizadas, establecimientos públicos o empresas industriales y comerciales del estado, adscritos o vinculados al Ministerio de Defensa Nacional. Diario Oficial n..$^{3}$ 38.634. https://www.redjurista.com/Documents/decreto_2701_ de_1988_ministerio_de_defensa_nacional.aspx\#/

Ministerio de Hacienda y Crédito Público (1976, 11 de mayo). Decreto 929 de 1976. Por el cual se establece el régimen de prestaciones sociales de los funcionarios y empleados de la Contraloría General de la República y 
sus familiares. Diario Oficial n. ${ }^{0}$ 34.577. https://www.ustarizabogados.com/porvenir/images/decretos/ DECRETO-929-DE-1976.pdf

Ministerio de Justicia (1971, 27 de marzo). Decreto 546 de 1971. Por el cual se establece el régimen de seguridad y protección social de los funcionarios y empleados de la Rama Jurisdiccional, del Ministerio Público y de sus familiares. Diario Oficial n. ${ }^{\circ}$ 33.339. https://www.redjurista.com/Documents/decreto_546_de_1971_ ministerio_de_justicia.aspx\#/

Ministerio del Trabajo y Seguridad Social (1990, 18 de abril). Decreto 0758 de 1990. Por el cual se aprueba el Acuerdo número 049 de febrero 1 de 1990 emanado del Consejo Nacional de Seguros Sociales Obligatorios. Diario Oficial n. ${ }^{0}$ 39.303. https://www.redjurista.com/Documents/ decreto_758_de_1990_ministerio_de_trabajo_y_seguridad_social.aspx\#/

Muñoz, A., Romero, C., Téllez, J., Tuesta, D. (2009). Confianza en el futuro: propuesta para un mejor sistema de pensiones en Colombia. Editorial Norma S.A. https://www.bbvaresearch.com/wp-content/uploads/ mult/Confianza_en_el_futuro_tcm346-219339.pdf

Ortiz, A., Arroyave, M. (2015). Origen histórico del sistema pensional colombiano y sus problemáticas Itesis de grado, Universidad Autónoma Latinoamericanal. Repositorio Institucional. http://repository.unaula. edu.co:8080/bitstream/123456789/592/1/unaula_rep_pre_der_2015_sistema_pensional.pdf

Presidencia de la República (1991). Decreto Nº 2067 de 1991. https://www.alcaldiabogota.gov.co/sisjur/ normas/Normal $. j s p ? i=30150$

Presidencia de la República (1991). Decreto Nº 2591 de 1991. http://www.secretariasenado.gov.co/ senado/basedoc/decreto_2591_1991.html\#34

Rodas, D. y Arenas, V. (2019). La imprescriptibilidad del derecho al incremento pensional en Colombia. [Monografía para optar por el título de abogado, Universidad Autónoma Latinoamericanal. Repositorio Institucional. http://repository.unaula.edu.co:8080/bitstream/123456789/1339/1/unaula_rep_pre_ der_2019_imprescriptibilidad_incremento_pensional.pdf.

Salcedo, D. (2017). El sistema pensional colombiano: desafíos después de la reforma y re-reforma. El Cotidiano, 204, 128-135. https://www.redalyc.org/articulo.oa?id=32553151012

Santander, A. (s. f.). Análisis de la jurisprudencia que resuelve sobre la prescripción de los incrementos pensionales consagrados en el artículo 21 del Acuerdo 049 de 1990 aprobado por el Decreto 758 de 1990. [Artículo en línea, Repositorio Universidad Santo Tomas]. https://repository.usta.edu. co/bitstream/handle/1 1634/20806/2 109Alexandra\%20Santander.pdf?sequence=4EisAllowed=y

Tribunal Superior del Distrito Judicial de Guadalajara de Buga (2019, 25 de septiembre). Sentencia aprobada mediante Acta 33. Confirma la sentencia consultada. http://ratioiurisprudentia.ramajudicial. gov.co/Jurisprudencia/ 